Geografia e Ordenamento do Território, Revista Electrónica

Centro de Estudos de Geografia e Ordenamento do Território

http://cegot.org

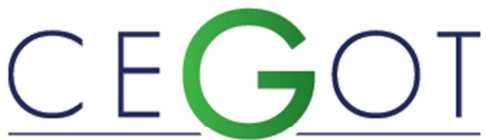

ISSN : 2182-1267

Centro de Estudos de Geografia e Ordenamento do Território

Motta, R.

reginasamotta@hotmail.com

\title{
Integração nacional e sul-americana: velho debate, novas con(tra)dições
}

Referência: Motta, R. (2014). Integração nacional e sul-americana: velho debate, novas con(tra)dições. Revista de Geografia e Ordenamento do Território (GOT), n.o 5 (junho). Centro de Estudos de Geografia e Ordenamento do Território, p. 181-205

\section{Resumo}

Pretende-se aqui, analisar o processo de integração nacional no Brasil a partir de 1950 buscando na trajetória do planejamento estatal - nas fases autoritária e pósredemocratização (neoliberal) -, as mudanças de discurso legitimadores das politicas de desenvolvimento, além de entender, como foram sendo construídas a dar legitimidade às políticas de desenvolvimento regional e de como elas foram necessárias em determinado momento e, em outro, "desnecessárias". Assim, as ideias do regional no contexto brasileiro é trabalhada a partir do contexto socioeconômico ao qual se insere: a atuação de agentes econômicos e a interferência mínima do Estado neoliberal implicaram na concentração de riqueza, seletividade espacial e produção ampliada da pobreza.

Palavras-Chave: Integração Nacional, Discurso Legitimador, Política governamental, Economia não paritária.

\section{Abstract}

The intention here is to analyze the process of national integration in Brazil since 1950 seeking the path of state planning - in phases and post-authoritarian democratization 
(neoliberal) - changes in legitimizing the political development discourse, and understanding, as they were being built to give legitimacy to regional development policies and how they were necessary at a given moment and in another, "unnecessary". Thus, the ideas of the Brazilian regional context is crafted from the socioeconomic context in which it operates: the actions of economic agents and minimal interference from the neoliberal state resulted in the concentration of wealth, spatial selectivity and expanded production of poverty.

Keywords: National Integration; Legitimizing Speech, Government Policy, Economics not Equal.

\section{Reconsiderando a temática do desenvolvimento regional}

Nas duas últimas décadas do século XX aprofundou-se a crise econômica gerada pelo modelo de desenvolvimento que o Brasil adotou na década de 50. Esse modelo esteve pautado no ideário do "Brasil Potência" (Abreu, 2001), cujo marco referencial foi o Plano de Metas, de Juscelino Kubitscheck, que, durante os anos da ditadura militar (1964$1985^{1}$ ), viveu seu auge, expresso no discurso do "milagre econômico brasileiro" (19681974), decorrente das políticas de desenvolvimento regional.

Trata-se de uma conjuntura oriunda de macroprojetos políticos implementados e voltados à integração e "conquista" do território nacional, tendo como fio condutor a industrialização via planejamento governamental.

Contudo, a não vitória desse processo encontrou muitas adversidades à frente: a realidade socioeconômica da maioria populacional, no que tange educação, profissionalização, mercado, entre outros aspectos correlacionados, não se constituem em fatores somatórios, ou engrenagem apropriada.

Por conseguinte, em 1989 vê-se sendo demonstrado um diagnóstico da falência das políticas de desenvolvimento regional (Lencioni, 1989), pelo menos daquela sua faceta de política de Estado; e que deve não só às fragilidades da temática ${ }^{2}$, mas também de

${ }^{1}$ É importante salientar que o país pós 1974 já mostrava sinais de debilidade econômica, porém aparentemente, devido o financiamento público, a economia apresentava certo crescimento.

${ }^{2}$ A esse respeito, conforme a autora, [...] Estamos num momento em que não seria surpreendente reconhecer que a região - referência fundamental de grande parte dessas políticas, como conceito e realidade -, carece de consistência, tanto teórica como empírica. Além disso, muitas análises de desenvolvimento regional ainda pagam tributo 
uma reorientação discursiva que utilizava o regional como eixo central de legitimação de políticas.

É como nos propõe também essa autora salientando que a [...] ascensão e queda de um tema vai além das exigências de uma elaboração intelectual. Esta faz parte do processo de legitimação de forças políticas vivas, cuja ação social consegue institucionalizar alguns temas como resposta a demandas culturais e ideológicas de uma época (LENCIONI, p. 119).

Essa constatação levou-a a se perguntar, consequentemente, se a época do regional já passara.

Entretanto, o que veremos a partir dos desdobramentos e contradições das políticas de desenvolvimento regional, e, do falimento desse modelo de desenvolvimento é que: novas demandas conceituais/ideológicas - num processo de legitimação de novos agentes econômicos - são necessárias em resposta às demandas do capital hegemônico e, obviamente, um novo arranjo espacial é necessário para atender às essas novas demandas.

Ou seja, até a noção de região também se modifica, nesse movimento. [...] trata-se de indagar como as políticas de desenvolvimento regional cumpriram seu papel e porque a temática regional não cumpre mais uma função legitimadora das políticas de desenvolvimento; (LENCIONI, 1989, p. 120).

No entanto, essas políticas apesar de "falidas" promoveram a ocupação do território e a integração do mercado nacional, como afirma Limonad (2004, p. 64) "as regionalizações e propostas de desenvolvimento regional elaboradas durante o período da ditadura militar possuíam um caráter geopolítico preciso na medida em que tinham por objetivo a ocupação do território".

Trata-se de políticas desenvolvimentistas que foram elaboradas a partir da criação, em 1962, do Ministério do Planejamento, e, que estavam sob influência de intelectuais como: Roberto Campos e Delfim Netto. A expressão máxima dessas políticas estão bem cristalizadas na "famosa" fala de Delfim de que, teoricamente, era preciso primeiro

a uma orientação empirista e funcionalista, diante do temor de um trabalho teórico, que revaslaria por mitos acadêmicos. LENCIONI (1989, p. 119). 
aumentar o bolo (aumento da renda via poupança interna), para depois reparti-lo (promoção da distribuição da renda), ideia que permeou o Programa de Ação Econômica do Governo (PAEG) sendo este o primeiro plano econômico elaborado pelo governo militar pós 1964.

E que, dessa forma, pode nos levar a crer que essas políticas acabaram tendo seus fundamentos influenciados por dualidades oriundas de desequilíbrios regionais o Sudeste como "desenvolvido" e moderno, enquanto que o Nordeste, representado pelo "subdesenvolvimento" e pelo arcaísmo.

Lencioni (1989, p. 121) entende que [...] a explicação do desenvolvimento desigual, pelo chamados desequilíbrios regionais, ao se reduzirem à essa bipolaridade - Nordeste, Sudeste - abriram caminho para a transposição de análises dualistas no entendimento das disparidades regionais de desenvolvimento.

Nessas conjunturas, cria-se conforme a Lei no 3.692 em 01 de dezembro de 1959 a SUDENE (Superintendência para o Desenvolvimento do Nordeste) com o objetivo de buscar solucionar o atraso daquela região a partir da intensificação do processo de industrialização. Neste contexto o Centro-Oeste ficaria sob jurisdição da Superintendência de Desenvolvimento da Região Centro-Oeste (SUDECO) que foi criada pela Lei no 5.365, de 01 de dezembro de 1967, na gestão Costa e Silva.

Como consequência, a SUDECO e suas congêneres (SUDENE e SUDAM) [...] vêm confirmar a existência de uma racionalidade dirigida e introduzida como pensamento ideológico dominante, que é propagada através de seus programas e planos (ABREU, 2004, p. 177 e 178).

Ainda, sobre esse período, no Centro-Oeste, Galindo e Santos observam que:

(...) ao analisar os diversos programas percebe-se que os objetivos reais $\mathrm{da}$ política têm apontado sempre na mesma direção, qual seja, o benefício para uma mesma classe social, detentora do poder político. A defasagem entre os objetivos aparentes e os reais não pode ser considerada erro administrativo ou deficiência no planejamento, mas consequência da visão elitista e autocrática que caracteriza os processos de decisão na esfera política (GALINDO e SANTOS, 1995, p.164). 
Para Lencioni (1989, p. 125) os anos do milagre foram marcados por três características: o crescimento da industrialização de bens duráveis visando atender principalmente a classe média (automóveis, TV a cores, eletrodomésticos, entre outros), a alteração da estrutura de exportações de produtos manufaturados amparados por incentivos governamentais e contraditóriamente a retração da indústria de bens não duráveis como a indútria textil do Nordeste por carecer de medidas de proteção do capital investido.

Desta maneira, conforme Lencioni (1989, p. 125) o modelo de crescimento a qualquer preço teve seus dias contados. A capacidade de importação se restringiu, a produção dos meios de produção foi sendo duramente afetada, na medida em que a taxa de inversão não se podia fazer independentemente da capacidade de importar. Nisso, com a intenção de conter gastos públicos, mais uma vez se vê utilizada a estratégia por muitos reclamados: adoção de restrições de incentivos fiscais e creditícios, expansão da arrecadação tributária e o maior controle sobre as empresas estatais.

Para Abreu (2001, p. 206) a consequência foi que durante a década de 1980 em que se diminuiu a capacidade de captação de recursos no exterior, já que, pelos altos juros, a poupança externa não era mais tão atraente.

Também, com o crescimento da dívida nacional, os bancos, impuseram mais regras e dificuldades ao financiamento diante das altas taxas de inflação, o que acabou repercutindo na renda do trabalhador.

Afora ainda o arrocho salarial: com violenta queda do valor real do salário mínimo - que foi reduzido praticamente à metade - permitindo o acesso dos trabalhadores apenas às migalhas daquele bolo que se dizia em crescimento, no auge das políticas desenvolvimentistas.

Diante deste quadro,

a crise se aprofundava. Saídas foram tentadas. A busca por créditos externos, a ida ao FMI e aos acordos firmados para o ajustamento da economia, acabaram significando o agravamento da recessão econômica. Sendo assim outros setores sociais, as classes médias urbanas foram alvo de ônus, desde a elevação dos impostos até a poupança forçada via contração salarial. 0 abismo havia chegado à classe média e assim assombrava o grande mercado 
consumidor da indústria nacional, que era pega, também, pelo lado da realização da mercadoria (LENCIONI, 1989, p. 127).

É nesse momento que os órgãos de desenvolvimento regional e outros programas materializaram o chamado esvaziamento; representado pela crescente fraqueza das lideranças políticas regionais frente ao quadro altamente recessivo da economia nacional.

E é, portanto, após a falência desse modelo de desenvolvimento e da legitimação discursiva a partir do regional, que Limonad (2004) vai se questionar o porquê da retomada da Região no atual período, ou ainda a quem ou para que servem as regionalizações?

Devemos recordar que a região a despeito de todas as adjetivações que a acompanham e perseguem, é uma construção social, que atende interesses políticos precisos, mesmo se tratando de uma região funcional, ou da região natural. A sua taxonomia e categorização científica podem inclusive seguir distintos procedimentos científico-metodológicos e ter por base critérios e cartografias precisas (LIMONAD, 2004, p. 57).

Não é preciso muito para averiguar tal constatação, que é possível a partir da avaliação das políticas de desenvolvimento regional, que entendiam o espaço enquanto um contínuo físico e social.

Atualmente, essa forma de entender a Região não é suficiente para a elaboração de políticas públicas direcionadas. Novos elementos terão que ser adicionados e conforme Limonad (2004) [...] a região é produto do pensamento social, de práticas hegemônicas e contra-hegemônicas, assim, é uma representação, e parte da construção social do espaço de uma sociedade (LIMONAD, 2004, p. 57).

É como se percebe na afirmações de Silveira (1999): “a Região constrói-se a partir da ação de distintos agentes em múltiplas escalas articuladas geograficamente, permitindo que o local e o global se afirmem ou se neguem dialeticamente" e de Limonad (2004) que destaca que: "o capital em seu estágio atual, globalizado tem muita clareza da nova realidade regional ao redesenhar o mapa geoeconômico do país, associando-se ao 
Estado, que desempenha o papel de articulador do país aos fluxos globais, no sentido de torná-lo competitivo internacionalmente" (LIMONAD, 2004, p. 58).

Questão essa, presente nos programas dos mandatos do presidente Fernando Henrique Cardoso - "Brasil em Ação" e "Avança Brasil" -, que definiram eixos de integração e polos de investimento, momento em que o Banco Nacional de Desenvolvimento Econômico e Social (BNDES) passou a desempenhar importante papel na articulação da relação Estado-Empresa, visando o desenvolvimento econômico regional.

Deste modo para Limonad (2004) a política regional está novamente na pauta das problemáticas, visto que, o governo de Luís Inácio Lula da Silva ressuscitou algumas instituições ${ }^{3}$ como a SUDENE e SUDAM, porém com diferentes conteúdos de suas predecessoras.

Para a mesma autora faz-se necessário contextualizar que a inserção do Brasil na atual divisão internacional do trabalho alterou-se significativamente, o que permitiu ao País assumir um papel intermediário entre os países avançados e os países de capitalismo tardio, deixando de ser [...] um mero fornecedor de matérias-primas, alimentos in natura e semi-manufaturados [...] para assumir o patamar de país emergente que [...] apesar do tímido volume das exportações, engloba uma série de produtos de alto valor agregado como: aviões, automóveis, caminhões, carnes, entre outros (LIMONAD, 2004, p. 61).

Assim, considera que há muito o mercado nacional deixou de se restringir apenas ao mercado interno ou da América do Sul (MERCOSUL), atualmente visa também outros mercados como a China, a União Européia, os países árabes, africanos, Rússia e os EUA, "superando" desta maneira a especialização regional derivada da prática de planejamento governamental e suas representações.

\section{Globalização, reestruturação produtiva e governabilidade}

Dentre os movimentos que afetam a dinâmica e a forma de funcionamento da economia mundial, numa conjuntura de conexões-emaranhamento, faz-se necessário trazer à clareza dos fatos algumas ações que operam na esfera político-institucional, e como esses movimentos se desdobram nacionalmente. Estes processos estão relacionados a

${ }^{3}$ Embora não apareça no texto da professora Ester Limonad (2004), a SUDECO também foi recriada no mencionado governo. 
mundialização capitalista, a partir de 1990, e, segundo Mizusaki (2009), com novas transformações técnico-produtivas e organizacionais, visando beneficiar o capital ${ }^{4}$, como consequência contextual da crise do sistema desde os anos de 1960, concretizados no "aumento da inflação na queda da taxa de lucro das empresas, no esgotamento do padrão de acumulação fordista, na crise do Welfare State ${ }^{5}$ no aumento excessivo da esfera financeira" (MIZUSAKI, 2009, p. 133-134).

Araújo (2000) destaca que nos anos 1990 acentuou-se o processo de desenvolvimento do sistema capitalista monopolista, pois é a "etapa avançada e específica do movimento de internacionalização capitalista", como define Chesnais apud Araujo (2000, p. 09-12), sendo marcado por "fatos hegemônicos", caracterizados em três movimentos "que afetam profundamente a dinâmica e a forma de funcionamento da economia mundial operando na esfera político-institucional" associadamente: o primeiro é o da globalização caracterizada pela internacionalização dos mercados, dos principais fluxos econômicos e da atuação dos principais agentes econômicos; o segundo é o movimento de crise do regime de acumulação anterior, expressando dificuldade para o capital na reprodução ampliada na esfera produtiva mundial; o terceiro, e mais intenso, é o da

${ }^{4}$ Mizusaki (2009, p. 134) esclarece que Antunes (2000, p. 31), fundamentado nas teorias de Meszáros, distingue capital de capitalismo. O capital seria todo um sistema de metabolismo social (composto pelo tripé capital, trabalho e Estado) que envolve as funções reprodutivas sociais subordinadas ao imperativo do capital. Nessa perspectiva, o capitalismo seria apenas uma das suas formas de realização. Pelo fato de o sistema de metabolismo social do capital ser expansionista, mundializado, destrutivo e incontrolável, a sua estruturação aponta para uma crise estrutural pela rapidez com que vem processando a tendência de reduzir o valor de uso das mercadorias, pois as crises, não são mais alternadas por ciclos longos, já que, agora, são mais frequentes e contínuas.

" A base teórica do "Welfare State", o Estado do bem-estar social, foi apresentada na década de 1930 pelo economista inglês John Maynard Keynes (1883-1946) após a Depressão de 1929. Para Myrdal (1932), criador do conceito, que se consolidou no período posterior à Segunda Guerra Mundial nos Estados Unidos e em boa parte dos países da Europa, o Estado do bem-estar social tinha como finalidade e característica básica a intervenção estatal nas atividades econômicas, regulando-as, subsidiando-as, executando grandes investimentos e obras, redistribuindo rendimentos, visando sempre, pelo menos teoricamente, ao bem-estar da maioria da população. A idéia era romper com o centenário princípio do liberalismo, que rejeitava qualquer função intervencionista do Estado (TOMAZI, 2010, p. 100). 
financeirização da riqueza, a possibilidade crescente dos agentes econômicos "de ampliar seu patrimônio, de valorizar seu capital na esfera da economia" (ARAÚJO, 2000, p. 09-12).

Reafirma Chesnais (1996, p. 25):

Para os turiferários da globalização, a necessária adaptação pressupõe que a liberalização e a desregulamentação sejam levados a cabo, que as empresas tenham absoluta liberdade de movimentos e que todos os campos da vida social, sem exceção, sejam submetidos à valorização do capital privado (CHESNAIS, 1996, p. 25).

É devido à necessidade de se adequar os territórios ao imperativo dos impactos que o processo impõe que se torna imprescindível a reestruturação produtiva, conforme salienta Araújo (2000, p. 10):

Quando se fala em reestruturação produtiva, está se referindo ao conjunto de importantes transformações, também em curso, que definem um novo "padrão produtivo". São mudanças das quais emergem novos setores dinâmicos na economia mundial (informática, telecomunicações, robótica, produção de novos materiais, entre outros); mudanças no como se produz e que resultam, sobretudo, da revolução científico-tecnológica produzida pela crescente hegemonia do paradigma microeletrônico, que quebra a cadeia fordista e cria as condições para a produção flexivel: mudanças nas formas de organizar e gerir a produção, organizar os meios que a geram e os homens que a realizam; mudanças nas formas de organizar os mercados, com a tendência à formação de grandes blocos econômicos, entre outras. (ARAÚJO, 2000, p. 10).

Araújo (2000) afirma que, a partir de 1990, no bojo deste processo, identifica-se, também, a "emergência de novos discursos ideológicos de desenvolvimento entre as quais se destaca o desenvolvimento local e regional em detrimento da Reforma Agrária" (Thomaz Júnior, 2006) e o desenvolvimento sustentável, sem o questionamento da estrutura da sociedade que provoca a destruição dos recursos nas dimensões 
socioculturais, econômicas, políticas, ambientais, indicando uma tendência de atuação de novos e importantes atores:

Em muitas áreas do País, atores locais têm-se articulado para pensar e propor estratégias de desenvolvimento local e regional. Planos estratégicos municipais e regionais têm-se tornado cada vez mais frequentes, embora isso não dispense a ação coordenadora do Estado Nacional, como ocorre na Alemanha ou na Itália dos dias atuais.

[...] Assim, se, de um lado, parece claro que as tendências recentes apontam para o aprofundamento das diferenciações regionais herdadas do passado e para a fragmentação do Brasil - destacando os "focos de competitividade e de dinamismo" do "resto" do País para articulá-los à economia global -, de outro lado, há contratendências importantes vindas de baixo para cima.

[...] outros agentes estão se contrapondo a isso e articulam movimentos de base territorial que clamam por articulação em nível nacional e incluem-na em suas práticas. É o caso de movimentos como o dos Trabalhadores Rurais SemTerra, o dos desalojados pelos projetos de barragens, entre outros (ARAÚJO, 2000, p. 22).

Para Araújo (2000) a economia brasileira, a partir deste período, foi marcada pela desnacionalização do sistema bancário, da base produtiva, pelas políticas de redução de tributos, como o Imposto de Circulação de Mercadorias e Serviços (ICMS), entre outros, que, a partir da criação da Lei Kandir de 1996, incentivou a exportação de matériasprimas para fora do país e interferiu na arrecadação de cada estado brasileiro, como no caso do Mato Grosso do Sul, promovendo a "guerra fiscal" entre as unidades federativas, a partir de alíquotas diferenciadas, utilizadas como atrativo de novos investimentos industriais, o que, concretamente, como coloca Mizusaki (2009), intensificou a mobilidade espacial do capital na busca de mais lucro, como ocorreu com a expansão da área plantada de cana-de-açúcar no território meridional sul-matogrossense, na produção dos agrocombustíveis em detrimento da produção de alimentos agrícolas.

Nessas premissas, considera-se que a dimensão político-institucional é instrumentalizada a partir de vinculações de racionalidade liberal, que acaba adquirindo 
o prefixo neo (neoliberal), já como demonstrativo de adequação às exigências da contemporaneidade; adequações essas que, em território nacional, são percebidas após escolhas estratégicas do Governo pós-redemocratização.

Nesse sentido, passa a ser frustrante, como aponta Acselrad (2000, p. 85), que após o processo de redemocratização, o país não demonstra dar inicio a reais transformações em suas estruturas sociais.

Pelo contrário, a desigualdade social se acentua: o impacto conjugado da desigualdade crescente e da falta de crença na efetividade dos canais da transformação social pela via da ação coletiva organizada não podia deixar de minar as bases de credibilidade da própria instituição democrática (ACSELRAD, 2000, p. 85).

Ainda, o fosso formado entre pobres e ricos não resulta apenas das escolhas macroeconômicas dos governos, mas também do [...] enfraquecimento do poder de barganha dos atores socais que tiveram peso decisivo nas lutas contra a ditadura, [...] crescentemente vitimados pela insuficiência das taxas de crescimento econômico, pelos padrões de mudança técnica e, consequentemente, pelo desemprego. (ACSELRAD, 2000, p. 85).

Nesse movimento, o próprio Estado vê suas condições de regulação/gestão territorial, frente às ações dos agentes econômicos globais, reduzida. A esse respeito, Ratner (2000, p. 16) assevera que:

[...] Conglomerados e corporações transacionais apropriam-se do poder decisório do Estado, decidindo onde, quando e quanto investir. A suposta dispersão do capital sob forma de mercado de ações é invocada como legitimação e aparente democratização do sistema. Na realidade, um punhado de megainvestidores controla riquezas equivalestes à renda da metade da população mundial e detém o poder político sem responsabilidades socais, tudo em nome da liberdade de mercado. Por outro lado aparece a fragilidade do Estado, perdendo credibilidade e capacidade de governança. Abstenção em massa, manipulação do eleitorado pela mídia e enormes contribuições financeiras de corporações para os candidatos da elite reduzirem a credibilidade dos governos eleitos, numa democracia representativa fictícia (RATNER , 2000, p. 16). 
Confluindo em sentido semelhante, Acselrad (2000, p. 87), entende que os Estados nacionais serão reduzidos à condição de Estados comerciais abertos, que acabam moldando-se aos processos de mundialização do capital, uma vez que,

[...] Erigida a capacidade de inserção internacional como principal fator de dinamização econômica, o discurso da competitividade foi sendo também evocado para legitimar o desemprego - tido por custo social inevitável atribuído à própria "incompetência" dos trabalhadores - e induzir a mobilização "guerreira" para o trabalho intensificado dos que não perderam seus empregos (ACSELRAD, 2000, p. 87).

Assim, a reorientação estratégica assumida pelo Estado acaba se mostrando desastrosa, já que o mercado não distribui as riquezas geradas pela economia global. Essa reorientação significa, também, em uma mudança nas formas de legitimação do Estado: enquanto no período Desenvolvimentista a legitimidade advinha de investimentos/gastos públicos, no Neoliberal, há a redução de despesas e a dissolução do modo de redistribuição do período anterior, ou seja, uma atuação intencionalmente minimizada, principalmente na esfera social (saúde, educação, entre outras.).

Nessa perspectiva, o modelo neoliberal, [...] caracterizado pela abertura $e$ desregulamentação dos mercados, a privatização das empresas públicas e a precarização das relações de trabalho, aprofundou a assimetria social e econômica e transformou os milhões de desempregados em marginalizados e excluídos do convívio social (RATNER , 2000, p. 17).

De acordo com a afirmação do autor pode-se pensar que após décadas de liberação e desregulamentação do comércio, de privatizações, de abertura imposta às economias mais débeis, conforme acordo com as normas e preceitos do Consenso de Washington que [...] seus mentores e responsáveis estão confusos e inseguros diante das consequências desastrosas manifestadas em todos os quadrantes (RATNER, 2000, p. 12). 
Acrescenta-se ainda, em complementação à ideia anterior dos ajustes "políticos" referenciados no Consenso de Washington - como assevera Acselrad (2000) que no âmbito das políticas públicas,

[...] difundiu-se a crença na racionalidade que decorre dos ajustes de mercado e das negociações efetuadas em espaços decisórios segmentados, encurtaram-se os horizontes temporais das decisões concertadas; substitui-se a política operada em escalas abrangentes pelos procedimentos técnicos acionados em escalas locais fragmentárias [...] (ACSELRAD, 2000, p. 87).

Nesse contexto de "crise do planejamento", surgem-se inovações discursivas que, conforme Acselrad (2000, p. 88), a noção de "governança", é uma das mais sugestivas e integra a literatura do Banco Mundial e [...] nasce do esforço conceitual de técnicos que buscavam legitimar a ação das agências multilaterais de desenvolvimento em países onde os Estados nacionais afiguravam-se corruptos ou com baixos índices de governabilidade [...]. Nesse sentido, [...] a gestão da governabilidade é identificada como a capacidade de reduzir as incertezas para os capitais mundializados, de eliminar as margens de possibilidade de que regras $e$ instituições econômicas venham a ser alteradas (ACSELRAD, 2000, p. 89).

Assim, percebe-se claramente que as medidas tidas como de "boa governabilidade" estão longe de dar respostas aos problemas desencadeados por esse tipo de desenvolvimento, além delas preverem a "desgovernamentalização" do Estado, ou mesmo a "despolitização" de um certo número de funções governamentais como destaca Acselrad (2000, p. 90):

A "boa governança", tal como entendida pelos governos que, no Brasil recente, aplicaram o receituário liberal, abdicando de sua responsabilidade para com as políticas sociais, a educação e o meio ambiente, é aquela, consequentemente, que instituiu a figura do "bom pobre" - invisível e que assume a si próprio e aos seus sem nada pedir à coletividade -, subordinando a saúde da população à saúde dos bancos e a sustentabilidade do meio ambiente à sustentabilidade dos fluxos financeiros especulativos (ACSELRAD, 2000, p. 90). 
Considerando essa "ausência" do Estado, Acselrad (2000, p 91) coloca que o país vem sendo imerso num processo de "pós-democracia consensual", [...] caracterizado pelo empobrecimento dos litígios, pelo "desaparecimento da política" e pela designação de certos segmentos sociais como aptos à negociação com o Estado na condição de "parceiros" [...]. Assim, os fóruns e conselhos, apesar de tornarem-se mais "participativos", são cada vez menos decisórios.

Portanto, essa democracia fictícia (Ratner, 2000), marca um período de atuação globalizada do capital hegemônico, que acabou acentuando as desigualdades da estrutura social brasileira.

Confirma Ratner (2000, p. 13) que:

As propostas de mudança esbarram numa estrutura de poder composta pelas forças conservadoras que historicamente exercem o poder, em aliança com grupos ou partidos supostamente modernizadores, uma coalizão que resiste aos movimentos populares democratizantes. Existe, portanto, uma contradição profunda entre a legalidade do exercício do poder pelos governos eleitos e a legitimidade de suas ações durante a vigência de seu mandato (RATNER, 2000, p. 13).

O autor critica ainda uma possível solução via financiamento, pelo grande capital, de ações filantrópicas desempenhadas pelo Terceiro Setor ${ }^{6}$, já que essa [...] filantropia seletiva e a "pinga-gotas" não compensa a ausência de responsabilidade moral de empresas perante seus empregados e as comunidades locais, empobrecidos pelos baixos salários, e a destruição sistemática do meio ambiente, nem a inoperância das políticas públicas (RATNER , 2000, p. 13). Portanto, explicita que essas medidas parciais não conseguirão alterar a dinâmica do sistema de exploração da força de trabalho e de destruição do ambiente.

${ }^{6}$ Cardoso (1997) considera o Terceiro Setor como "um espaço de participação e experimentação de novos modos de pensar e agir sobre a realidade social". Sua afirmação tem o grande mérito de romper a dicotomia entre público e privado, na qual público era sinônimo de estatal e privado de empresarial. "Estamos vendo o surgimento de uma esfera pública não-estatal e de iniciativas privadas com sentido público" (CARDOSO, 1997). 


\section{A emergência de novas regionalizações}

Conforme discussão apresentada sobre o falimento das políticas regionais de desenvolvimento - pelo menos daquele modelo proposto pelo Estado interventor, via planejamento autoritário de caráter desenvolvimentista -, e a supremacia da onda neoliberal que inunda o país, novas tendências à regionalização se configurarão nacionalmente, embora, grande parte delas acabe reafirmando áreas já dinâmicas em períodos anteriores, mantendo, portanto, aquelas disparidades já conhecidas.

Nesse sentido, se ao Sudeste coube a concentração industrial, às demais regiões restou servir aquela primeira, com o fornecimento de matéria-prima; prática que começa a ser rompida com a eleição de áreas dinâmicas e dinamizadoras em território nacional, sob a promoção de uma nítida desconcentração industrial. Porém, fato que não ameaçou a supremacia do Sudeste, que nesse atual período, em específico a cidade de São Paulo, expressa uma centralidade da gestão de empresas e do fluxo de capital que circula em todo o país.

Portanto, a proposta é elucidar a trajetória da afirmação dessa nova regionalização, que atua em locais precisos, especializando-os em nome do grande capital. Por outro lado, não se pode esquecer que esse processo, concentrador e centralizador, atua não só na geração de riqueza, mas também na formação de aglomerados de pobreza (Hasbaert, 2004), que tendem a aumentar em volume e em quantidade frente à essa presença passiva do Estado em relação à atuação dos agentes econômicos globais.

Assim, entende-se que, acentuada a crise financeira na década de 1980, a década de 1990 é marcada pelas novas escolhas governamentais no sentido de superação dessa crise pela via da inserção competitiva no mercado global; o que implica, portanto, num redirecionamento, a partir deste período, no processo de integração do mercado interno e, consequentemente, nas políticas regionais ou na ausência delas. Nessa conjuntura o governo Collor e o governo de Fernando Henrique Cardoso promoveram a abertura financeira e comercial do país, ganhando destaque a noção de integração competitiva diferentemente da anterior que visava a integração do território nacional esta tem como prioridade a internacionalização da economia do país. 
De acordo com Araújo (1999, p. 13) [...] ao invés de consolidar a integração do mercado interno, processo que vinha se acelerando nas décadas anteriores, passa-se a priorizar a inserção no mercado mundial das empresas, segmentos e espaços econômicos mais competitivos [...] (ARAÚJO, 1999, p. 13).

Essa inserção no mercado mundial leva ao desaparecimento de diversas empresas, diminuindo-as em quantidade num processo que se deu via fechamento, reestruturação, considerando que o que de fato marcou esse período foram as fusões como a exemplo do que ocorreu com os bancos.

Dessa forma, competitivamente, como coloca Araújo (1999, p. 15) algumas áreas vão sendo priorizadas pelos agentes econômicos:

\begin{abstract}
Do ponto de vista da dinâmica regional, tal opção estratégica tende a valorizar os espaços econômicos portadores de empresas e segmentos mais competitivos, com condições, portanto, de ampliar com mais rapidez sua internacionalização ou de resistir com mais força ao "choque de competição" praticado nos anos 90, no Brasil. E esse processo secundariza as regiões menos competitivas, as mais negativamente impactadas pela competição exacerbada ou as que se encontram em reestruturação. (ARAÚJO, 1999, p.
\end{abstract} $15)$.

Nesse sentido, há a ampliação da diferenciação e a heterogeneidade intra-regionais já que esse processo cria "ilhas dinâmicas" no interior das macrorregiões, propondo assim, uma fragmentação do território nacional.

Limonad (2004), considerando que, se por um lado há a globalização da economia, da cultura e de padrões de consumo e de vida, por outro, há um tecido social heterogêneo e um espaço onde a diversidade impera. Portanto,

[...] A constante dissolução e recriação da sociedade industrial [...], resulta na constante (re)estruturação e (dis)solução do espaço a cada momento - neste sentido tende a haver uma mudança em processos espaciais como a urbanização e a industrialização que contribuem para a (re)estruturação territorial e para a conformação de "novas" regiões e formas de regionalização (LIMONAD, 2004, p. 54 e 55).

Num mesmo direcionamento, Araújo (1999), assevera que [...] ao contrário do que se poderia esperar, a globalização reforças as estratégias de especialização regional [...]. 
Assim a [...] nova organização dos espaços nacionais tende a resultar, de um lado, da dinâmica da produção regionalizada das grandes empresas (atores globais) e, de outro, da resposta dos Estados nacionais para enfrentar os impactos regionais seletivos da globalização [...] (ARAÚJO, 1999, p. 16).

Com base em Santos (1996), Limonad (2004, p. 59) salienta que, se até a terceira revolução industrial [...] as regionalizações faziam-se horizontalmente a partir da extensão das áreas de influencia e da denominação e organização de uma extensão territorial a partir de uma cidade ou rede de cidade [...], com as novas tecnologias de comunicação, as regionalizações passaram a constituir-se verticalmente, mediante a articulação, a inter-relação entre pontos selecionados do/no território.

Portanto, conforme esta autora, aquela especialização espacial da produção começou a ser timidamente rompida, em virtude da nova divisão internacional do trabalho, das novas condições de produção, das necessidades do capital e das disputas inter-regionais. Também, a mesma autora como Araújo (1999) utiliza a implantação difusa ${ }^{7}$ de montadoras de automóveis em diferentes partes do país para elucidar essa questão, que quebra com a lógica de regiões especializadas (Sudeste - industrial; Centro-Oeste e o Sul - fronteira agropecuária; Nordeste - bens intermediários químicos e têxteis; Norte mineração e extrativismo), ligada ao planejamento estatal desenvolvimentista.

Conforme Limonad (2004, p. 62 - 63):

A indústria brasileira tem passado por um forte processo de modernização e desconcentração espacial nos últimos anos. A guerra fiscal entre as várias unidades da Federação, os salários baixos nas regiões menos desenvolvidas, a proximidade de fontes de matéria-prima, o nível da infraestrutura local e o

\footnotetext{
${ }^{7}$ Apesar de ter ocorrido essa difusão pelo território nacional, não seria correto entender que ela ocorreu de uma forma aleatória. Para Araújo esse processo de desconcentração industrial, que também é uma reconcentração em outras áreas, possui forças que [...] atuam no sentido da concentração de investimentos nas áreas já mais dinâmicas $e$ competitivas do País. Ressaltam-se, em especial os novos requisitos locacionais da acumulação flexível, com a melhor oferta de recursos humanos qualificados, maior proximidade dos centros de produção de conhecimento e tecnologia, maior e mais infraestrutura econômica, proximidade dos mercados consumidores de mais alta renda [...]. ARAUJO (1999, p.16).
} 
desenvolvimento do Mercosul têm provocado o deslocamento da indústria em direção a diferentes regiões [...] (LIMONAD, 2004, p. 63-63).

Nisso, tem-se como denomina Limonad (2004, p. 63) o movimento de dispersão concentrada, já que se caracteriza por uma [...] dispersão geográfica das plantas industriais pelo território nacional e uma reconcentração econômica e financeira das sedes administrativas e financeiras no Sudeste.

Deste modo evidencia-se que não há possibilidade de crescimento ilimitado da economia de mercado e conforme Araújo (1999), devido a formação de regiões não competitivas, ocorre a exacerbação das desigualdades sociais e dos impactos ambientais promovidos nessa fase pelo modo de produção capitalista.

Contribui Ratner (2000, p. 13), no que tange a quebra dos estigmas de crescimento ilimitado da economia de mercado, alertando que:

\begin{abstract}
construído sobre as premissas de um crescimento linear, cartesiano, e alimentado pelos fluxos de investimentos estrangeiros, o modelo abstraiu ou ignorou invariáveis importantes do sistema. Desprezando as dimensões sociais e políticas do processo de crescimento econômico, não se atentou para as consequências das fusões, investimentos especulativos e a transferência da propriedade e controle de empresas nacionais para mãos estrangeiras. Esse tipo de investimento não gera empregos e contribui, por via da reengenharia e da flexibilização das relações de trabalho, para a redução paulatina da massa de salários. Completada por uma política fiscal perversa que impacta negativamente no nível de renda e poupança, portanto na capacidade de investimento interno, entra-se num circulo vicioso que impele cada vez mais recorrer às fontes de financiamento externas, aumentando a dívida, pressionando as taxas de juros cambial, com efeitos negativos no balanço de pagamentos, onerado pelos compromissos de remessa, de dividendos, de royalties e, obviamente, parcelas do principal da dívida (RATNER, 2000, p. 13).
\end{abstract}

Portanto, paralela às especializações produtivas de determinadas áreas e/ou regiões, há a formação de aglomerados de exclusão (Hasbaert, 2004) que podem estar imbricados ou mesmo sobrepostos aos locais que concentram grande volume de capital, na sua forma virtualizada ou material. Evidentemente que a materialização do grande capital 
no território por meio de obras, plantas industriais ou mesmo pelo controle da matériaprima, tende a camuflar toda e qualquer tipo de contradição presente nessa realidade.

Há dessa forma, a formação de uma representação de espaço que se consolida como hegemônica, construída no interior do modo de produção, que atribui a pobreza e a inclusão precária, como afirma Hasbaert (2004) como incompetência dos próprios sujeitos nessa condição.

Convém considerar que Hasbaert (2004, p.177) entende o espaço como uma dimensão dotada de três momentos, já identificados por Lefebvre (espaço percebido ou "praticado", concebido ou representado e vivido através de suas imagens e símbolos), a partir da sua relação indissociável com a dimensão temporal.

Desta maneira apoiamo-nos na ideia do autor porque entendemos que a realidade não é formada por uma única representação, e sim por uma diversidade de representações. Nesse sentido, essa etapa do modo de produção capitalista a qual estamos vinculados, onde parece, o tempo ter suprimido o espaço, há constantemente territorializações precárias, ou no sentido do mito, uma crescente desterritorialização da sociedade.

Para aqueles que estão condicionados, via opção, a se deslocar em diversos pontos do mundo, a globalização se apresenta como um elemento positivo. Porém, àqueles que estão em constante disputa pelos seus territórios, que antes de serem local de produção, são locais de reprodução da vida, do ser enquanto humano, esta etapa do modo de produção pode se mostrar perversa, já que promove o embate de agentes da economia mundo com grupos minoritários, por exemplo.

Essa realidade ressignifica a ideia de regionalização, pois abandona aquele seu sentido inicial, muito ligado aos movimentos do capital. Movimentos que parecem ter suprimido o espaço em função do tempo e, consequentemente, ter decretado o fim dos territórios. No que tange essa afirmação da ocorrência do fim dos territórios, ou seja, da desterritorialização como fenômeno que significa, entre outras interpretações, a supressão do espaço, Haesbaert (2004, p.19) contrapõe afirmando que:

A chamada desterritorialização, ou melhor, des-re-territorialização, e, conseqüentemente, os atuais processos de regionalização, estão fortemente vinculados ao fenômeno da compressão tempo-espaço - não no sentido de uma "superação do espaço pelo tempo", ou de um "fim das distâncias", mas 
de um emaranhado complexo de "geometrias de poder" de um espaço social profundamente desigual e diferenciado (HAESBAERT, 2004, p. 19).

A famosa ruptura entre modernidade e pós-modernidade, a qual reflete em uma nova ideia de tempo e espaço, agora de forma intensa e mais evidente, em um meio técnicocientífico e informacional, como denominou Santos (1996), gera um ambiente de discussões sobre essa nova experiência, dita por alguns, desterritorializada de tempoespaço.

Em meio a essas discussões, e considerando todas as especificidades de uma temática tão complexa, Haesbaert (2004) assevera que a desterritorialização [...] antes de significar desmaterialização, dissolução das distâncias, deslocalização de firmas ou debilitação dos controles fronteiriços, é um processo de exclusão social, ou melhor, de exclusão socioespacial.

Assim, usando também o termo precarização socioespacial, afirma que, nesta sociedade da pós-modernidade, o processo de exclusão é promovido por um sistema econômico altamente concentrador, sendo este o principal responsável pela desterritorialização.

Essa estrutura de funcionamento mundial assistida, de forma mais acentuada, desde a década de 1990, gera o que Haesbaert (2004) denomina de aglomerados humanos de exclusão; e passa a agrupar processos sociais e componentes espaciais para pensar a regionalização em pleno século XXI, após esta temática ter sido considerada ultrapassada, sobretudo pela geografia. Há o questionamento de como territórios-zona, territórios-rede, multiterritorialidade podem contribuir para uma nova regionalização do mundo e, mais especificadamente do Brasil.

Para Haesbaert (2004):

É preciso partir do pressuposto de que regionalização não é apenas o produto do exercício acadêmico de identificação de "regiões" como recortes coerentes, representativos de uma sempre problemática "diferenciação de áreas", mas um processo social complexo de formação de contextos regionais - contextos que não se resumem á "lógica areal" ou zonal (como nos tradicionais territórios-zona), mas que incorporam, de forma não-dicotômica, a lógica "reticular" ou das redes (como territórios-rede) e a "i-lógica" dos 
processos de exclusão que produzem os "aglomerados humanos de exclusão" (HAESBAERT, 2004, p. 23).

Nesse sentido, emerge, a partir da crescente fluidez, o elemento rede na constituição de territórios,

[...] conectando suas parcelas descontínuas, temos o fortalecimento não mais de um mosaico padrão de unidades territoriais em área, vistas muitas vezes de maneira exclusiva entre si e às quais denominamos territórios-zona, mas uma miríade de "territórios-rede" marcada pela descontinuidade e pela fragmentação (articulada) que possibilita a passagem constante de um território a outro, num jogo que denominaremos aqui, muito mais do que de desterritorialização ou de declínio dos territórios, da sua "explosão" ou, em termos mais consistentes, de uma "multiterritorialidade". (HASBAERT, 2004, p. 179).

Pensar a regionalização a partir desses termos não se trata de um desafio simples. Ele é sim inovador e coloca em voga as principais questões-contradições a serem superadas pela sociedade - como é o caso de dar continuidade ao processo globalizante, criador de multiterritorialidades, que possibilita a passagem constante de um território a outro; e criador, paralelamente, de exclusão - eliminando ou ao menos diminuindo esses processos geradores, e intensificadores, de desigualdades.

É interessante ressaltar aqui a necessidade de se considerar mais alguns pressupostos para tal desafio.

Somos levados, mais uma vez, a buscar superar a dicotomia material-ideal, o território envolvendo, ao mesmo tempo, a dimensão social concreta das relações sociais e o conjunto de representações sobre o espaço ou o “imaginário geográfico" que também move essas relações (HAESBAERT, 2004, p. 46).

Ou seja, é preciso se desvencilhar dos compromissos imutáveis com correntes filosóficas e científicas muito definidas. Devemos nos arriscar em um entrecruzamento de influências teóricas, sem esquecer que se trata de um movimento multifacetado. 
Podemos exemplificar melhor essa necessidade voltando ao desafio de promover uma nova regionalização. No caso de se trabalhar para a inserção dos aglomerados de exclusão, e tendo como exemplo os grupos de camponeses sem terra e, em uma outra via, o grupo de indígenas, que também reivindica uma base territorial, é necessário desenvolver a capacidade de distinguir as especificidades de cada grupo.

Para isso, é importante considerar a dimensão concreta e imaginária, a material e a simbólica-cultural das relações sociais.

Considerando o grupo dos camponeses sem-terra, a reivindicação pela terra possui, assim como considera a perspectiva materialista da luta de classes no marxismo, um sentido, sobretudo, econômico, sendo a identidade do grupo construída na própria luta pela terra como instrumento de trabalho. Já para os grupos indígenas, que se movimentam pela delimitação e controle de suas reservas, [...] a desterritorialização não se fundamenta tanto na exclusão do acesso à terra enquanto meio de produção (solos férteis, florestas ricas em produtos extrativos) mas, primeiro, num nível simbólicocultural [...] (Haesbaert, 2004, p. 67), considerando, nessa perspectiva, o próprio imaginário geográfico, condensado simbolicamente em alguns elementos do espaço, como o rio, uma cachoeira ou um trecho de floresta.

Deste modo baseado na geometria euclidiana e respondendo ao desafio de se utilizar os territórios-zonas e os territórios-rede como fios suleadores é preciso compreender como elementos do espaço as superfícies, os pontos a as linhas, e, a partir daí, organizar o sistema territorial, cuja produção combina sempre as "invariantes": malhas, nós e redes. Não obstante:

Nem só de "métricas" logicamente estruturadas compõe-se o espaço social contemporâneo. Ele envolve outras dinâmicas, ainda mais instáveis e/ou imprevisíveis, que não são passíveis de identificação em termos de áreas ou redes, sejam elas arborescentes ou rizomáticas, hierárquicas ou complementares. O principal processo social responsável por esses "espaços de instabilidade" é o que se chama de exclusão ou, como prefere Martins (1997), inclusão precária, já que exclusão não deve ser vista como um movimento dicotômico ou alheio às dinâmicas de precarização da inserção social (HAESBAERT, 2000, p. 24). 
É partir desta percepção do autor que se dá a proposta para incorporação das dinâmicas de territorialização precária, dos grupos sociais que estão mergulhados numa geografia instável de territórios confusamente delimitados, emergindo-se como um terceiro elemento, somado as perspectivas de área e de rede, os aglomerados humanos de exclusão.

Os grupos pertencentes a esses aglomerados representam a desterritorialização contemporânea. Consiste, na maioria dos casos, em "massas" que terminam à margem do sistema, permanecem "fora" do circuito produtivo. Portanto, para o autor,

[...] uma nova regionalização deve incorporar a diversidade de espaçosterritórios produzidos na pós (ou ultra) modernidade (os “múltiplos territórios" existentes no mundo contemporâneo), cientes de que, muito mais do que o universo globalizado de comunicação e mesmo ação à distancia, vivemos o mundo do acirramento das desigualdades, da exclusão ( ou da inclusão precária) crescente e da mobilidade complexa que participa da configuração regional re-produzindo relações de poder profundamente desiguais (HAESBAERT, 2000, p. 25).

Nesse sentido, segundo Limonad (2004, p. 57), é preciso pensar as razões para se proceder às regionalizações, ou seja, "para que regionalizar"? Ou "para quem servem as regionalizações"?

Portanto, ao planejamento cabe a missão de incorporar novos elementos às atuais regionalizações, que têm como enfrentamento um território completamente fragmentado e complexo do ponto de vista inter-regional.

\section{Considerações finais}

As políticas de desenvolvimento regional, como instrumento uno para diminuir as desigualdades sociais e regionais e, de quebra, proporcionar a integração do território, mostrou-se insuficiente para tal. Marcada pelas contradições intrínsecas ao modelo de desenvolvimento capitalista, muitas das benesses de tal forma de atuação do Estado ficaram apenas no discurso.

Como esclarece Lencioni (1989, p. 128) [...] o tema regional não está caduco na história, nem consiste em discurso ultrapassado; está perdendo, é claro, a sua base institucional 
de se colocar como questão de Estado como agente de mobilidade espacial do capital industrial (LENCIONI, 1989, p. 128).

Para a mesma autora o atual movimento comprometeu o "sonho e o discurso" de se diminuir as disparidades regionais de desenvolvimento assentadas nesta mobilidade espacial, [...] o que deve ser desafiador do ponto de vista acadêmico para o estudo do regional de maneira a explicar o fenômeno "em vez de se esquivar" (LENCIONI, 1989, p. 128).

Nesse sentido, a desconcentração industrial que promoveu a especialização e a fragmentação de áreas intra-regionais, possibilitou a construção de "centros" e "periferias" no interior das Regiões, quebrando com a unicidade do Sudeste enquanto a única região que possuía um parque industrial.

$\mathrm{Na}$ atual fase do modo de produção capitalista, é certo que, novamente o Sudeste passa a exercer uma centralidade, porém, agora passa a concentrar a maior parte das sedes de empresas e, portanto, concentra o maior volume do capital "virtual" - estratégia rentista da financeirização da economia.

A abertura comercial e financeira do país deve ser entendida como uma aproximação do Estado para com os agentes econômicos - de atuação global. Essa aproximação tem repercussão de forma catastrófica nos países de capitalismo tardio; significou para o Brasil a desnacionalização e privatização de empresas, a desregulamentação da economia, o aumento das desigualdades, a acentuação da pobreza.

Também, a fragmentação do território nacional, que passa a ser representada pelas disputas fiscais entre as unidades da federação por investimentos externos, ou seja, o governo passa a estar sujeito às decisões do capital hegemônico, perdendo a sua capacidade decisória.

Assim, frente às novas possibilidades e razões/finalidades de regionalização, terminamos com uma pergunta, não mais questionando a legitimidade da temática, mas se seria possível, na contradição entre o capitalismo global e a soberania nacional, a construção de políticas em nível regional, já que as decisões na atualidade estão pautadas cada vez mais na escala global? 


\section{Referências bibliográficas}

ABREU, Silvana de. O papel da SUDECO no processo de racionalização do espaço mato-grossense: planejamento e integração nacional. In: LAMOSO, Lisandra Pereira. Transportes e políticas públicas em Mato Grosso do Sul. Dourados, MS: Editora da UFGD, 2008. p.117-133.

ABREU, Silvana de. O papel da Sudeco no processo de racionalização do espaço mato-grossense: planejamento e integração nacional. In: MORETTI, E. C. et alie. Geografia e produção regional: sociedade e meio ambiente. Campo Grande: Edufms, 2004.

ABREU, Silvana de. Planejamento governamental: a Sudeco no espaço mato-grossense - contexto, propósitos e contradições. 2001. Tese (Doutorado em Geografia) - USP/FFLCH, São Paulo.

ABREU, Silvana de. Racionalização e Ideologia: O domínio do capital no espaço mato-grossense. Terra Livre, no 21. São Paulo, AGB, 2003. P.169.181.

ACSELRAD, Henri. Sociedade Civil, Democracia e Governabilidade. In: RATNER, Henrique. Brasil no Limiar do Século XXI. São Paulo: Edusp, 2000.

BECKER, B. Modernidade e gestão do território no Brasil. Espaço \& Debates - Brasil Pós 80: Novo Estado, Novas Territorialidades. Neru - Ano XI, no32 - 1991 - p. 47-56.

CARDOSO, Ruth C. L. "Fortalecimento da sociedade civil". In: IOSCHPE, Evelyn Berg (org.). 3o setor: desenvolvimento social sustentado. São Paulo/Rio de Janeiro: Gife/Paz e Terra, 1997.

CHESNAIS, F. A mundialização do capital. São Paulo: Xamã, 1996.

HASBAERT, Rogério. Desterritorialização, Multiterritorialidade e Regionalização. In: LIMONAD, E.; HAESBAERT, R; MOREIRA, R; org. Brasil século XXI por uma nova regionalização - agentes, processos e escalas. São Paulo: Max Limonad, 2004.

GALINDO, O.; SANTOS, V. M. Centro-Oeste: evolução recente da economia regional. In: AFONSO, R. Federalismo no Brasil. São Paulo: Fundap/Edunesp, 1995.

LENCIONI, Sandra. A mudança do discurso desenvolvimentista face à crise da economia. A falência das políticas de desenvolvimento regional. Revista do Departamento de Geografia da USP, São Paulo: 1989 p. 119-128.

LIMONAD, Ester. Brasil Século XXI, Regionalizar para Que? Para Quem? In: LIMONAD, E.; HAESBAERT, R; MOREIRA, R; org. Brasil século XXI por uma nova regionalização - agentes, processos e escalas. São Paulo: Max Limonad, 2004.

MIZUSAKI, M. Y. Território e reestruturação produtiva na avicultura. Dourados-MS: EDUFGD, 2009.

RATNER, Henrique. Prefácio. In: . Brasil no Limiar do Século XXI. São Paulo: Edusp, 2000.

SANTOS, Milton. A Natureza do Espaço. São Paulo: Hucitec, 1996.

SILVEIRA, Maria Laura. Um país, uma região, fim de século e modernidades na Argentina. São Paulo: FAPESP - Laboplan/USP.

THOMAZ JÚNIOR, A. Se camponês, se operário! Limites e perspectivas para a compreensão da classe trabalhadora no Brasil. In: Geografia e trabalho no século XXI: Volume 2. THOMAZ JÚNIOR, A.; CARVALHAL, M. D.; CARVALHAL, T. B.; (orgs). São Paulo: Viena, 2006. 